\title{
Considering multiple criteria for social categorization can reduce intergroup bias
}

Article

Accepted Version

final pre-publication version

Hall, N. R. and Crisp, R. J. (2005) Considering multiple criteria for social categorization can reduce intergroup bias.

Personality and Social Psychology Bulletin, 31 (10). pp. 14351444. ISSN 0146-1672 doi:

https://doi.org/10.1177/0146167205276084 Available at https://centaur.reading.ac.uk/4486/

It is advisable to refer to the publisher's version if you intend to cite from the work. See Guidance on citing.

Published version at: http://dx.doi.org/10.1177/0146167205276084

To link to this article DOI: http://dx.doi.org/10.1177/0146167205276084

Publisher: SAGE Publications

All outputs in CentAUR are protected by Intellectual Property Rights law, including copyright law. Copyright and IPR is retained by the creators or other copyright holders. Terms and conditions for use of this material are defined in the End User Agreement.

\section{www.reading.ac.uk/centaur}

\section{CentAUR}

Central Archive at the University of Reading 
Reading's research outputs online 
MS PSPB-03-075 Version 4

Running Head: MULTIPLE CATEGORIZATION

Considering multiple criteria for social categorization can reduce intergroup bias

Natalie R. Hall \& Richard J. Crisp

University of Birmingham

Word count: 7237

Author Note

Natalie R. Hall, Richard J. Crisp, School of Psychology, University of Birmingham.

This research was funded by a British Academy research grant (SG-34045) to R. J. Crisp and an Economic and Social Research Council doctoral studentship (PTA-030-2002-00889) to N. R.

Hall.

Correspondence concerning this article should be addressed to N.R. Hall or R. J. Crisp at the School of Psychology, University of Birmingham, Edgbaston, Birmingham, B15 2TT. Tel: +44

(0)121 4142227 or +44 (0)121 414 3335. Fax: + 44 (0)121 414 4897. E-mail: nrh873@bham.ac.uk or r.crisp@bham.ac.uk.

This is the final pre-publication version of this article including all responses to referees comments. The definitive version of this article can be found here DOI: 10.1177/0146167205276084 


\begin{abstract}
Two experiments tested the notion that considering multiple criteria for social categorization can reduce intergroup bias. In both experiments, participants were required to consider alternative ways in which people could be classified, other than an initially salient intergroup dichotomy. In Experiment 1 we found that generating alternative social classifications that were unrelated to an initial target dichotomy reduced intergroup bias compared to a control condition. In Experiment 2 we replicated this effect and found that unrelated, but not related, categorizations were necessary to reduce bias. This paper adds support to the view that increasing categorical complexity is a useful tool in bias reduction. We discuss these findings in the context of a developing model of multiple categorization effects.
\end{abstract}

Keywords: INTERGROUP BIAS, MULTIPLE SOCIAL CATEGORIZATION, IDENTITY COMPLEXITY

Considering multiple criteria for social categorization can reduce intergroup bias 
Processing resources are a valuable commodity for the social perceiver. For the most part, classifying others into broad groupings - social categorization -- is a useful shortcut for navigating the social world and thus saving such resources (Fiske \& Taylor, 1991; Hamilton, 1979; Macrae \& Bodenhausen, 2001). The usefulness of this mechanism can be demonstrated by the observation that it is used even in artificial and arbitrary contexts (e.g., Rabbie \& Horowitz, 1969; Tajfel, 1982; Tajfel, Flament, Billig \& Bundy, 1971; for a review see Bourhis, Sachdev, \& Gagnon 1994). The cognitive efficacy of social categorization comes, however, with some drawbacks: it is the mental pre-requisite for intergroup bias. People in the perceiver's own groups tend to be reliably and consistently evaluated more positively than those in other groups (e.g., Brewer, 1979, Mullen, Brown \& Smith, 1992). In this article, we explore the potential for reducing such bias by contravening the inherent 'functionality' of categorization.

The usefulness of social categorization

Categorization causes an accentuation of differences between, and similarities within, social groups (Doise, 1978; McGarty \& Penny, 1988; Tajfel \& Wilkes, 1963). According to many theorists, it is this process of differentiation between groups that, in part, leads to ingroup favouritism (for examples see the Category Differentiation Model, Doise, 1978; Social Identity Theory, Tajfel \& Turner, 1979; Self-Categorization Theory, Turner, Hogg, Oakes, Reicher \& Wetherall, 1987). There are differences between these accounts. For some categorization is a simplifying mechanism, for others a way of ascribing meaning to the social context, but they all rest on the notion that to observe intergroup bias there must first exist a distinct cognitive dichotomization into 'us' and 'them' (see Maass \& Schaller, 1989; Tajfel, 1969), and they are all linked by a common principle: that categorization is on some level psychologically 'useful'. 
Social categorization can be considered useful because it is adaptive, providing a quick and sufficient understanding of what is occurring in the social world (van Knippenberg \& Dijksterhuis, 2000). Group-based judgments represent a slice of knowledge that can be applied to a target person who fits the category (e.g., Sherman, Macrae, \& Bodenhausen, 2000). Categorical thinking is cognitively economical -- providing the maximum output of information with the least cognitive effort (Macrae \& Bodenhausen, 2001). It reduces the need to process incoming data by providing the perceiver with group-based expectancies; and directs attention and processing resources to expectancy relevant information (Hastie, 1981; Stangor \& Macmillian, 1992). Using social categories to guide processing therefore reduces the cognitive resources required for person perception by providing a set of pre-conceived expectations about the target (Bodenhausen, 1992; Macrae, Stangor \& Milne, 1994; Oakes \& Turner, 1990).

Although categorical thinking can be advantageous from this functional perspective, stereotypes associated with category activation are often inaccurate when applied to individual targets. Furthermore, such activated social categories can cause selective perception, interpretation, and memory (Heilman, 1995). This can be problematic when the (sometimes negative) stereotypic information generated is used to guide impression formation. The question we addressed in this research was whether removing the cognitive efficacy of categorization would prevent its use in guiding evaluative judgments in person perception. We suggest that one way to achieve this is by making multiple alternative bases for social categorization salient for the perceiver.

\section{Multiple social categorization}

A considerable amount of work has focused on the notion that changing the categorical representation of groups can correspondingly change intergroup evaluations. Levine and Campbell (1972) drew attention to the reduced conflict associated with cultures having a crossed societal 
structure. They noted that in contexts characterized by social structures that comprise loyalties to multiple groups, some of which coincide, and some of which are in conflict, lower levels of intergroup conflict tend to be observed. Later, this idea emerged in social psychological work on intergroup relations. Deschamps and Doise (1978) suggested that by simultaneously combining two cross-cutting dimensions of social categorization, opposing accentuation and assimilation principles would effectively cancel each other out and reduce intergroup bias. This approach of combining two cross-cutting categorizations has met with mixed success in terms of reducing intergroup bias (Brown \& Turner, 1979; Crisp, Hewstone, \& Rubin, 2001; Deschamps \& Doise, 1978; Vanbeselaere, 1987; 1996). The majority of studies produce a pattern of evaluation where any group associated with the ingroup is evaluated positively to some extent, but where negative evaluations are still directed towards those people who are outgroup according to both categorical criteria (Diehl, 1990; Ensari \& Miller, 1998; Hewstone, Islam \& Judd, 1993; Kenworthy, Canales, Weaver, \& Miller, 2003; Marcus-Newhall, Miller, Holtz \& Brewer, 1993; Urada \& Miller, 2000; Vanbeselaere, 1987; see Crisp \& Hewstone, 1999; Urban \& Miller, 1999 for reviews).

In contrast to focusing participants on two cross-cutting dimensions of categorization (Deschamps \& Doise, 1978; Vanbeselaere, 1987; 1996), considering more than two categorization criteria may uniquely lead to a 'decategorization' effect (Crisp et al., 2001). The reasoning is as follows: we know that participants are cognitively able to use two dimensions of social categorization under normal processing conditions (e.g., Vanbeselaere, 1987). As the number of categorization dimensions to consider increases, the intergroup context would become much more complex and the perceiver may no longer be able to easily determine on what basis they are similar to, or different from, the target person. There may be too many dimensions of membership to allow meaningful category conjunctions to form. Perceivers may be able to cognitively combine categories 
like 'single mother' or 'working parent' (see Hutter \& Crisp, in press), but they may find, for example, 'single, black, educated, working mother' more difficult, at least with respect to gaining any added value by processing information and making evaluative judgments heuristically. There may come a point in considering successive categorical dimensions when using a heuristic method of classification actually becomes inefficient relative to other methods of impression formation. The idea of multiple modes of processing is key to contemporary theories of person perception, and we suggest that the ideas outlined above regarding the effects of multiple categorization can be interpreted within the context of some well-established frameworks relating to impression formation.

\section{Categorization and decategorization}

Brewer's (1988) Dual Process Theory and Fiske and Neuberg's (1990) Continuum Model both consider person perception and impression formation to comprise of two distinct processes: categorization and individuation. The basic premise of Brewer's Dual Process Theory (1988) is that either a top-down category based approach or a bottom-up person based approach is used and this is analogous to a heuristic (category) versus systematic (individuated) approach to person perception. Fiske and Neuberg (1990) propose a continuum for impression formation where one extremity is category-based processing and the other is attribute (individuated) based processing. On this continuum people can be perceived as a representative of a group (category-based responding), or as an individual separate from any categorical identity (attribute-based responding). Fiske and Neuberg propose a system where an initial categorization will occur, followed by a confirmatory process to determine how good a fit there is between the category and target. If this is unsuccessful, then there will be a shift towards the individuated mode of perception by invoking an attribute-by-attribute approach to form an impression of the target person. As Fiske, Lin and Neuberg (1999) state: 
“...perceivers typically use category-oriented processes before they use attribute-orientated processes, and [that] if the category-oriented processes work well enough perceivers do not engage additional more attribute oriented processes" (pp. 236). Brewers' Dual Process Theory is based on similar principles and predicts that the mode of perception will change from the use of category based heuristics to a more systematic individuated mode of perception under conditions that either favor, or do not favor, one over the other. As Brewer and Harasty Feinstein (1999) note, the changes in processing outlined by the Dual Process Model map directly onto Fiske and Neuberg's impression formation continuum.

This switch in processing from using categorization to individuation can be termed decategorization. Decategorization results when initial categorizations of people as group members are overridden by a more comprehensive and differentiated perception of the individual (see Brewer \& Miller, 1984; Ensari \& Miller, 2001; Wilder, 1986). Once decategorization has occurred the target person should be primarily defined as an individual rather than a group member, which should remove category-based bias. Previous research has found that conditions that promote decategorization will encourage participants to favour the ingroup less (presumably because the judgment is being made on an appreciation of personal merit, not on the basis of pre-conceived categorical expectancies; see Brewer \& Miller, 1984; Krueger \& Rothbart, 1988; Miller \& Harrington, 1992). This change in the mode of processing should also allow the perceiver to develop a more personalized and less homogenous perception of ingroup and outgroup members (Ensari \& Miller, 2001; Fiske \& Neuberg, 1989).

We argue that considering multiple criteria for social categorization could produce a decategorization effect by virtue of the implied decrease in usefulness of any one dimension of social comparison. Decategorization is, however, an uncommon finding when only two dimensions of 
Multiple categorization 8

categorization are combined. Ensari and Miller (2001) directly compared personalized contact

(where participants are asked to consider unique attributes) with the traditional crossed

categorization approach (two dimensions of categorization). They found that intergroup bias was no longer moderated by shared ingroup memberships in the personalised contact condition, but this was not the case in the crossed categorization condition. This could be because participants are quite able (and appear to) consider two social categorizations simultaneously in memory and use them to guide evaluative judgments (Vanbeselaere, 1987; 1996).

However, as the number of category dimensions that need to be processed simultaneously increases then it may be that categorization, as a functional heuristic, becomes relatively inefficient, leading to a shift in orientation and a reduction in bias as outlined by Brewer's (1988) and Fiske and Neuberg's (1990) models. If perceivers experience conditions in which categorization becomes too complex to be functional then they may resort to a more individuated strategy for person perception. Correspondingly they should be less biased in their evaluations of ingroup and outgroup members, as these evaluations are no longer tied to group membership. By considering multiple criteria for social categorization, category-oriented processes may no longer provide the most functionally efficient or meaningful way of making judgments, and consequently perceivers may resort to a less biased approach to person perception.

In the context of the dual processing accounts of impression formation outlined above, we can make some clear predictions with respect to the effects of multiple categorization on intergroup evaluations. We thus tested the possibility that merely thinking about multiple alternative criteria for social categorization may decategorize person perception and reduce category-based ingroup favoritism.

Pilot study 
We initially carried out a pilot study to develop our multiple categorization task. We focused on undergraduate students' own university group membership versus a local rival university. Fortyfive undergraduate psychology students took part in individual sessions. All participants were informed that they would be asked to think about people who shared their university membership and people who did not. They were advised that the study was concerned with perceptions of people at different universities and how their respective qualities influence creativity and originality in working environments, and that all information would be compiled to assess the skills and abilities from graduates at different universities. Participants first completed a task that was ostensibly designed to test creativity, originality, and artistic merit. They were provided with a square piece of paper and asked to make a model that represented something in the real world by folding or tearing. They were allowed five minutes to complete this task. Participants in the experimental condition were then given the following instructions that constituted the critical task variable manipulation: "On an earlier page we asked you to think about your university affiliation. This is one possible way that people can define themselves, but there are many more. People can be similar or different from others not just according to one criterion, but often there are many and varied ways that people define themselves and others. We would like you to think of other groups that university students can use to define themselves (in addition to what university they are at)".

They were asked to provide a few written lines of elaboration on each alternative they came up with to reinforce the manipulation. They then completed a measure of group evaluation. Participants in the control condition did not complete a categorization task. Instead, they completed the group evaluations directly after making their paper model and received none of the instructions outlined above. 
Evaluations were measured by participants rating two paper models supposedly made by previous ingroup and outgroup participants ${ }^{1}$. Participants were asked to rate an ingrouper's and outgrouper's paper model according to creativity, originality and artistic merit on scales ranging from 0 (not at all) to 9 (very much so). These items were averaged to form indices of group evaluation: ingroup $\alpha=.721$, outgroup $\alpha=.722$. The group to which the model was affiliated and the order in which the models were presented was counterbalanced across conditions.

A 2 (task: control vs. multiple alternatives) x 2 (target: ingroup vs. outgroup) mixed ANOVA with repeated measures on second factor revealed a significant interaction between task and target $F(1,43)=4.77, p=.035$. This interaction reflected significant variation in intergroup bias (ingroup minus outgroup evaluations) as a function of task instructions, although not in the expected direction. Compared to the control condition $(M=-.300)$, intergroup bias was increased following the generation of multiple alternatives $(M=.707)^{2}$.

To investigate why we did not obtain the predicted reduction in bias we examined the specific alternative classifications generated by our participants in the experimental condition. We found that the majority of participants who completed the multiple categorization task (78\%) had actually produced classifications that were related in some way to the initial target dichotomy, rather than unrelated alternative ways of classifying the student groups. We define related category dimensions as those that are conceptually linked with the target categories. For example, what academic subject [major] is being studied is related to the context within which the target intergroup dichotomy (in this case 'students') is embedded. In contrast, unrelated category dimensions are those that are not conceptually linked with the target categories. For example, in our studies 'nationality' is unrelated to being a student. In this pilot study most participants had generated category dimensions like 'subject [major] studied' or 'hall or residence [fraternity/sorority]' as their 
alternative criteria. These alternatives are, however, directly related to the dimension 'student affiliation'. Few participants generated alternatives that were (as we had intended) unrelated to the target intergroup context (e.g., 'gender' or 'place of birth'). Interestingly, closer examination of the participants who had generated unrelated criteria did show a trend in the predicted direction (reduced bias).

We hypothesized that generation of related alternatives may not undermine the usefulness of the target dichotomy. Our reasoning was as follows. We know from previous work that whilst making a superordinate categorization salient can sometimes reduce intergroup bias (Gaertner \& Dovido, 2000), sometimes it can be ineffective, or even increase bias (see Hornsey \& Hogg, 2000). In their Ingroup Projection Model Mummendy and Wenzel (1999) draw upon Self-Categorization Theory (Turner, 1981; Turner, Hogg, Oakes, Reicher \& Weatherall, 1987) to argue that making a superordinate categorization salient can accentuate intergroup bias by introducing a relevant basis for social comparison. For example, fans of opposing sports teams may not be concerned with making ingroup favoring social comparisons against some other team until a relevant superordinate dimension is salient (i.e., they become rivals within the same league or competition).

We argue that the generation of related alternative categorizations may have similar effects. Thinking of related categorizations, by definition, should prime a relevant superordinate category dimension ('students') along which to compare the initial ingroup and outgroup student subgroups (defined by university affiliation). For example, categories related to university affiliation such as fraternity or sorority, or major studied, all make the superordinate category 'students' more salient and relevant. Put another way, thinking about bases for categorization other than the target dichotomy, but nonetheless related to it, creates a context of comparability in which ingroup favoring evaluations can serve to positively differentiate the ingroup from the outgroup (Tajfel \& 
Turner, 1979; see also Hogg \& Abrams, 1990; Jetten, Spears \& Manstead, 1996; 2001). Generation of related alternatives reinforces any potential comparability between the ingroup and outgroup, thus, ingroup favoritism should at best, remain pervasive, and at worse increase.

This pilot study therefore established an important pre-condition for the generation of multiple alternative classifications to reduce intergroup bias. To avoid priming a superordinate context of comparison as outlined above, it would be important to specify the generation of unrelated alternatives. In our first experiment, we therefore modified our instructions to achieve this goal.

\section{Experiment 1}

In this experiment the multiple categorization task instructions used in the pilot study were adapted to encourage participants to generate unrelated, not related, alternatives. We predicted that relative to a control condition, generation of unrelated alternatives would result in a decrease in intergroup bias.

\section{Method}

\section{Participants and Design}

Thirty-eight undergraduate psychology students (31 females, 7 males, with an overall mean age of 19) were randomly allocated to a 2 (task: control vs. multiple unrelated alternatives) x 2 (target: ingroup vs. outgroup) mixed design with repeated measures on the second factor. Participants received course credit for their involvement.

\section{Procedure}

The procedure was identical to the pilot study except that after having created the paper models, participants were given the multiple categorization instructions outlined above with the addition of an explicit instruction not to generate related alternatives (the student subgroups 'subject 
studied ' and 'hall of residence' were given as examples of alternatives to avoid). Participants were asked instead to generate "alternative ways people can vary independent from being a student", with the example given of 'Nationality'.

Participants in the control condition did not carry out the multiple categorization task and simply completed the evaluative measures (the typical baseline condition used in bias-reduction research) using the same paper models as employed in the pilot study.

\section{Dependant Measures}

Evaluations were measured by participants rating two paper models for creativity on a scale ranging from 0 (not at all) to 9 (very much so) ${ }^{3}$. One of the models ostensibly belonged to an ingroup member and one ostensibly belonging to an outgroup member. The group to which the model was affiliated and the order in which the models were presented was counterbalanced across conditions.

\section{Results $\mathcal{E}$ discussion}

One participant did not fully complete the dependant measures so was excluded from all further analysis. Four participants were removed on the grounds that they were suspicious about the aims of the experiment. Despite the refined multiple categorization instructions one participant exclusively produced related classifications so they were also excluded leaving an $N$ of 32 , with the remaining participants evenly distributed across conditions. Means and standard deviations can be found in Table 1.

\section{Manipulation check}

The categories generated by participants in the unrelated alternatives condition were judged for relatedness by two independent raters blind to the experimental hypotheses (participants in the control condition did not produce any categories). The judges were asked to rate the five category 
dimensions produced by each participant on a seven point scale as to whether they were unrelated (anchored at 1) or related (anchored at 7) to the initial target category dimension (student affiliation). Judges were provided with an example to clarify this distinction. An example of an unrelated category was 'hair color', an example of a related category was 'subject studied'. The two blind coders' ratings had acceptable inter-rater reliability, $r=.688, p=.002,\left(M_{\text {Judge } 1}=1.41\right.$, $\mathrm{SD}_{\text {Judge } 1}=.618$ vs. $\left.M_{\text {Judge } 2}=2.12, \mathrm{SD}_{\text {Judge } 2}=1.50\right)$ so were collapsed into one scale (by taking the mean of the two judges' ratings). A one sample t-test against the scale midpoint (4) revealed that on aggregate participants in the experimental condition had produced category dimensions that were unrelated to the target dimension of comparison ('students'), $t(16)=-9.35, p<.0005(M=1.76, \mathrm{SD}=.986)$.

\section{Evaluations}

A 2 (task) x 2 (target) mixed ANOVA with repeated measures on the second factor revealed no main effect of target, $F(1,30)=.868, p=.359$, nor of task, $F(1,30)=2.41, p=.131$. There was, however, the predicted interaction between task and target, $F(1,30)=7.57, p=.010$. In line with expectations, intergroup bias (ingroup minus outgroup evaluations) was lower following the generation of multiple unrelated alternative categorizations $(M=-.083)$ compared to the control condition $(M=1.67)^{4}$.

In summary, in line with predictions, intergroup bias was reduced following the generation of multiple unrelated categorizations compared to the control condition. The effect appeared to be driven predominantly by lowered ingroup evaluations, although some (non-significant) variation in outgroup evaluations was also observed. We know that intergroup bias is driven primarily by accentuated ingroup evaluations rather than outgroup derogation (Brewer, 1979). As such, reduced reliance on social categorization should, as we observed, result in a decrease in this ingroup favoritism (which is driving the bias in the first place), rather than a decrease in outgroup 
derogation. In Experiment 2 we sought to replicate and expand on these findings by directly comparing the effects of generating related versus unrelated alternative bases for categorization.

\section{Experiment 2}

Our pilot work indicated that thinking about related alternative classifications had a detrimental effect on intergroup relations, yet, we did not experimentally test this in Experiment 1. In Experiment 2 we therefore directly compared the two ways of framing the task. We had decided to use only a single-item evaluative measure in Experiment 1 so we expanded this to a three-item measure in this experiment. We expected reduced intergroup bias only for participants who were instructed to generate unrelated alternatives, compared to a control condition and a condition in which participants generated related alternatives.

\section{Method}

\section{Participants and Design}

Fifty-eight undergraduate psychology students (56 females; 2 males with a mean age of 19) were randomly allocated to a 3 (task: control vs. multiple unrelated alternatives vs. multiple related alternatives) x 2 (target: ingroup vs. outgroup) mixed design with repeated measures on the second factor. Participants took part in exchange for course credit.

\section{Procedure}

The procedure was the same as in Experiment 1 except we added a related alternatives condition. This version of the multiple categorization task comprised the same core instructions used in the pilot study but instead of the addition of an explicit instruction not to generate related alternatives, participants were specifically instructed to generate related alternatives (the student 
subgroups 'subject area' and 'hall of residence' were given as examples of alternatives to use). The 'unrelated' task was identical to that used in Experiment 1.

\section{Dependent measures}

Participants were asked to rate the ingroup and outgroup paper models according to creativity, originality and artistic merit on scales ranging from 0 (not at all) to 9 (very much so). These items were averaged to form indices of ingroup $(\alpha=.762)$ and outgroup $(\alpha=.810)$ evaluation respectively.

\section{Results $\mathcal{E}$ discussion}

Three participants were removed because they reported suspicion about the aims of the experiment, leaving an $N$ of 55 . Means and standard deviations for all measures can be found in Table 2.

\section{Manipulation check}

The categories generated by participants in the related and unrelated alternatives conditions were judged by the same two independent raters, blind to condition, as described in Experiment 1. We also used the same 'relatedness' scale for judging participants' responses as used in Experiment 1. The ratings produced by the two blind coders had acceptable inter-rater reliability, $r=.905, p<$ .001 unrelated: $M_{\text {Judge } 1}=1.20, \mathrm{SD}_{\text {Judge } 1}=.696$ vs. $M_{\text {Judge } 2}=1.85, \mathrm{SD}_{\text {Judge } 2}=1.18$, related: $M_{\text {Judge } 1}=$ $4.44, \mathrm{SD}_{\text {Judge } 1}=1.58$ vs. $\left.M_{\text {Judge } 2}=5.56, \mathrm{SD}_{\text {Judge } 2}=1.89\right)$ so were collapsed (by taking the mean) into one index. On this relatedness index, a t-test revealed a significant difference between related and unrelated conditions in the expected direction, $t(36)=-8.30, p<.0005,\left(M_{\text {unrelated }}=1.52\right.$ vs. $M_{\text {related }}=$ 5.00). Participants in the related condition generated categories that were more related to the student superordinate category context than those in the unrelated condition. One sample t-tests were carried out against the midpoint of the scale. Those in the related condition produced categories that 
were judged to be significantly related to the superordinate context, $t(17)=2.58 p=.020$. In contrast, those in the unrelated condition produced categories that were judged to be significantly unrelated to the superordinate context, $t(19)=-13.01, p<.0005$.

\section{Evaluations}

A 3 (task) x 2 (target) mixed ANOVA with repeated measures on the second factor revealed no main effect of target, $F(1,52)=.004, p=.950$, nor of task, $F(1,52)=.261, p=.771$. There was, however, the expected significant interaction between task and target, $F(2,52)=3.84, p=.028 .^{5}$ To explore the observed interaction, we again created an index of intergroup bias (ingroup minus outgroup evaluations). Consistent with the findings from Experiment 1, planned comparisons revealed less intergroup bias in the unrelated alternatives condition than in the control condition, $t$ $(52)=2.23 p=.030\left(M_{\text {control }}=.249\right.$, vs. $\left.M_{\text {unrelated }}=-.650\right)$. There was also less intergroup bias in the unrelated alternatives condition compared to the related alternatives condition, $t(52)=2.49, p=$ $.016\left(M_{\text {unrelated }}=-.650\right.$, vs. $\left.M_{\text {related }}=.338\right)$. Finally, there was no difference in intergroup bias between the control and the related alternatives condition, $t(52)=-.219, p=.828,\left(M_{\text {control }}=.249\right.$, vs. $M_{\text {related }}$ $=.338)$.

To summarize, in Experiment 2 we supported the idea that merely thinking about multiple alternative categorizations can reduce intergroup bias -- as long as they are unrelated to the initial intergroup context.

\section{General Discussion}

The aim of these experiments was to see if considering multiple alternative categorizations to the target ingroup versus outgroup categorization could reduce intergroup bias. In Experiment 1 we found that the generation of multiple unrelated alternatives led to the predicted bias-reduction effect. Experiment 2 built on these findings by replicating the decrease in intergroup bias following 
generation of multiple unrelated, but not related, categorization criteria. Overall, these studies have developed and refined a new approach to bias-reduction that is consistent with extant theoretical and empirical work on dual processing accounts of impression formation.

\section{Multiple alternatives and decategorization}

In Experiments 1 and 2 we found that the generation of multiple criteria for social categorization that were unrelated to the superordinate category comparison context 'students' reduced intergroup bias. The findings are consistent with the suggestion that the generation of multiple alternatives can encourage a shift in judgment orientation: if categorization is no longer functional in such contexts then judgments become less category-based (Brewer, 1988; Fiske $\&$ Neuberg, 1990), reducing ingroup favoritism.

There is an important caveat to this approach. Although the generation of multiple categories can reduce ingroup favoritism, it will only do so if the categories generated are unrelated to the superordinate category context. We believe that this is a crucial prerequisite for ensuring the success of multiple categorization approaches that aim to achieve decategorization. The generation of related categories may emphasize ingroup and outgroup comparability by highlighting the superordinate category context. Correspondingly, this may have no bias-reducing effect, or even result in a reactive increase in intergroup bias.

There are a number of potential explanations for what might cause the observed reduction in bias. We have argued that the generation of multiple categories may undermine the utility of the initial dichotomy and hence prevent the application of stereotypes relating to initial ingroups and outgroups. It is also possible, however, that producing numerous categorizations may reduce bias along the specified ingroup-outgroup categorization by reducing the degree to which the categorical 
distinction is salient for the perceiver. The decategorization effect may also be caused by a dilution of the original groups and their associated characteristics with many other categorizations and their stereotypes. The aim of the current research was to establish whether generation of multiple alternative categorizations can lead to a reduction in bias. Having now established this, more research is needed to delineate precisely the mechanisms that underlie this effect.

We should acknowledge that some aspects of our findings should be considered tentative. We have demonstrated the effect on only one dependent measure and with one paradigm thus, it is necessary for future work to test generalizability of the findings. In addition, while the general pattern of the findings across studies is consistent with predictions, there are also a number of specific inconsistencies across the three studies (relating to whether the locus of effect resides in moderation of ingroup evaluations, outgroup evaluations, or both). This further strengthens the call for replication with other procedures and measures.

\section{Category complexity and ingroup projection}

The multiple categorization approach used in this research may relate to the Ingroup Projection Model, Mummendy and Wenzel (1999). This model builds upon Self-Categorization Theory (Turner, 1981; Turner et al., 1987) to argue that superordinate categorization creates a context of comparability between ingroup and outgroup subgroups. Mummendey and Wenzel argue that in intergroup situations where the superordinate group is salient, the ingroup prototype will be projected on to the superordinate group. This ingroup projection may cause the outgroup to be perceived more negatively. If both the ingroup and outgroup are conceptualized as part of a superordinate category (a relevant comparison context), and the ingroup prototype has been projected onto the superordinate category, then the outgroup will be seen as deviating from the norm (Wenzel, Mummendey, Weber, \& Waldzus, 2003). The ingroup projected prototype will 
invariably be positive and hence the outgroup will be judged less positively by comparison (Wenzel, 2001). We argue that the generation of category dimensions related to the target dichotomy primes the superordinate categorization context, making the ingroup and outgroup similarly comparable. In contrast, generating unrelated alternatives reduces bias because it creates a context in which the utility of categorization per se is reduced - the context becomes too complex to usefully employ social categories.

Interestingly, the notion that category complexity can reduce intergroup bias is also reflected in the Ingroup Projection Model. Waldzus, Mummendey, Wenzel, and Weber (2003) found that projection of the ingroup prototype does not occur when the superordinate category is perceived itself as having a complex prototype. Although we argue that generating unrelated alternatives should lead to categorization being abandoned as a means of structuring social perception (so should not invoke the superordinate category), there are clear parallels between our model and the Ingroup Projection Model, in that both argue that complexity can reduce intergroup bias. Indeed, the notion that complexity is a good thing for intergroup relations is emerging as a key theme in work on intergroup relations. Roccas and Brewer's (2002) model of Social Identity Complexity argues that the more complex a perceiver's social identity, and the less overlap there is between their multiple ingroup identities, the less ingroup favoritism should be observed. Although not specific to ingroups, our research supports this general concept.

The findings we report reiterate the message that multiple categorization can reduce intergroup bias. Future research could examine some interesting possibilities regarding the integration of multiple categorization and ingroup projection via notions of complexity, and the corresponding potential for developing effective interventions to reduce intergroup bias. 
The aim of this research was to explore the potential for multiple social categorization to reduce intergroup bias. Could merely thinking about multiple alternative bases for social categorization be an effective strategy for promoting more egalitarianism in person perception? On the basis of these findings, we argue that the answer is yes - but with one important caveat. The way in which people are asked to consider multiple alternative criteria is critical to the observed effects. We found that categorization no longer defined evaluative judgment following multiple categorization providing that the categories considered were not related to the superordinate category context. These findings provide some important links between diverse literatures in impression formation and person perception, but perhaps more importantly, may also go some way to developing an integrated model of the implications of multiple categorization for intergroup relations.

\section{References}

Bodenhausen, G. V. (1992). Information processing functions of generic knowledge structures and their role in context effects in social judgement. In N. Schwartz \& S. Sudman (Eds.), Context effects in social and psychological research (pp.267-278). New York: Springer Verlag.

Bourhis, R. Y., Sachdev, I., \& Gagnon, A. (1994). Intergroup research with the Tajfel matrices: Methodological notes. In M. P. Zanna \& J. P. Olson (Eds.), The psychology of prejudice: The Ontario symposium, (pp. 209-232). New York: Random House.

Brewer, M. B. (1979). Ingroup bias in the minimal intergroup situation: A cognitivemotivational analysis. Psychological Bulletin, 86, 307-324. 
Brewer, M.B. (1988). A dual process model of impression formation. In T. K. Srull \& R. S. Wyer Jr (Eds.) Advances in Social cognition (pp. 1-36). Erlbaum: Hillsdale, NJ.

Brewer, M. B., \& Harasty Feinstein, A. S. (1999). Dual processes in the cognitive representation of persons and social categories. In S. Chaiken \& Y. Trope (Eds.) Dual process theories in social psychology (pp. 255-270). New York: Guilford.

Brewer, M. B., \& Miller, N. (1984). Beyond the contact hypothesis: Theoretical perspectives on desegregation. In N. Miller \& M. B. Brewer (Eds.), Groups in contact: The psychology of desegregation (pp. 281-302). San Diego, CA: Academic Press.

Brown, R. J., \& Turner, J. C. (1979). The criss-cross categorization effect in intergroup discrimination. British Journal of Social \& Clinical Psychology, 18, 371-383.

Crisp, R.J., \& Hewstone, M. (1999). Differential evaluation of crossed category groups: Patterns, processes, and reducing intergroup bias. Group Processes E Intergroup Relations, 2, 307-333.

Crisp, R. J., Hewstone, M., \& Rubin, M. (2001). Does multiple categorization reduce intergroup bias? Personality E Social Psychology Bulletin, 27, 76-89.

Deschamps, J. C., \& Doise, W. (1978). Crossed category memberships in intergroup relations. In H. Tajfel (Ed.), Differentiation between social groups (pp. 141-158). Cambridge: Cambridge University Press.

Diehl, M. (1990). The minimal group paradigm: Theoretical explanations and empirical findings. In W. Stroebe \& M. Hewstone (Eds.), European Reviere of Social Psychology, (Vol.1, pp. 263292). Chichester: Wiley.

Doise, W. (1978). Groups and individuals. Explanations in Social Psychology, Cambridge: Cambridge University Press. 
Ensari, N., \& Miller, N. (1998). Effect of affective reactions by the outgroup on preferences for crossed categorization discussion partners. Journal of Personality E Social Psychology, 75, 1503 1527.

Ensari, N., \& Miller, N. (2001). Decategorization and the reduction of bias in the crossed categorization paradigm. European Journal of Social psychology, 31, 193-216.

Fiske, S. T., Lin, M., \& Neuberg, S. L. (1999). The continuum model: ten years later. In S. Chaiken \& Y. Trope (Eds.) Dual process theories in social psychology (pp. 231-254). New York: Guilford.

Fiske, S. T., \& Neuberg, S. L. (1989). Category-based and individuating processes as a function of information and motivation: Evidence from our laboratory. In D. Bar-Tal, C. F. Graumann, A. W. Kruglanski, \& W. Stroebe (Eds.), Stereotyping and Prejudice: changing conceptions (pp. 83-104). Springer-Verlag: New York.

Fiske, S. T., \& Neuberg, S. L. (1990). A continuum of impression formation, from categorybased to individuating processes; Influences of information and motivation on attention and interpretation. In M. P. Zanna (Ed.), Advances in Experimental Social Psychology (Vol. 23, pp. 1-74). New York: Academic Press.

Fiske, S. T., \& Taylor, S. E. (1991). Social Cognition. New York: McGraw Hill. Gaertner, S. L., \& Dovidio, J. F. (2000). Reducing intergroup bias: The Common Ingroup Identity Model. Philadelphia, PA: The Psychology Press/Taylor \& Francis.

Hamilton, D. L. (1979). A cognitive attributional analysis of stereotyping. In L. Berkowitz (Ed.), Advances in Experimental Social Psychology (Vol. 12 pp.53-84). New York: Academic Press. 
Hastie, R. (1981). Schematic principles in human memory. In E. T. Higgins, C. P. Herman, \& M. P. Zanna (Eds.), Social cognition: The Ontario Symposium (Vol. 1, pp. 39-88). Hillsdale, NJ: Erlbaum.

Heilman, C. M. (1995). Sex stereotypes and their effects in the workplace: What we know and what we don't know. Journal of Social Behaviour and Personality, 10, 3-26.

Hewstone, M., Islam, M. R., \& Judd, C. M. (1993). Models of crossed categorizations and intergroup relations. Journal of Personality \& Social psychology, 64, 779-793.

Hogg, M. A., \& Abrams, D. (1990). Social motivation, self-esteem and social identity. In D. Abrams \& M. A. Hogg (Eds.), Social identity theory: Constructive and critical advances (pp. 28-47). New York: Harvester Wheatsheaf.

Hornsey, M. J., \& Hogg, M. A. (2000). Intergroup similarity and subgroup relations: Some implications for assimilation. Personality E Social Psychology Bulletin, 26, 948-958.

Hutter, R. R. H., \& Crisp, R. J. (in press). The composition of category conjunctions. Personality and Social Psychology Bulletin.

Jetten, J., Spears, R., \& Manstead, A. S. R. (1996). Intergroup norms and intergroup discrimination: Distinctive self-categorization and social identity effects. Journal of Personality $\mathcal{E}$ Social Psychology, 71, 1222-1233.

Jetten, J., Spears, R., \& Manstead, A. S. R. (2001). Similarity as a source of differentiation: the role of group identification. European Journal of Social Psychology, 31, 621-640.

Kenworthy, J. B., Canales, C. J., Weaver, K. D., \& Miller, N. (2003). Negative incidental affect and mood congruency in crossed categorization. Journal of Experimental Social Psychology, 39, 195-219. 
Krueger, J., \& Rothbart, M. (1988). Use of categorical and individuating information in making inferences about personality. Journal of Personality \& Social Psychology, 55, 187-95.

Levine, R. A., \& Campbell, D.T. (1972). Ethnocentrism: Theories of conflict, ethnic attitudes and group behaviour. New York: Wiley.

Maass, A., \& Schaller, M. (1989). Illusory correlation and social categorization- toward an integration of motivational and cognitive factors in stereotype. Journal of Personality \& Social Psychology, 56, 709-721.

Macrae, C. N., \& Bodenhausen, G. V. (2001). Social Cognition: Categorical person perception. British Journal of Psychology, 92, 239-255.

Macrae, C. N., Stangor, C. \& Milne, A. B. (1994). Activating social stereotypes: A functional analysis. Journal of Experimental Social Psychology, 30, 370-389.

Marcus-Newhall, A., Miller, N., Holtz, R., \& Brewer, M. B. (1993). Cross-cutting category memberships with role-assignment: a means of reducing intergroup bias. British Journal of Social Psychology, 32, 125-146.

McGarty, C., \& Penny, R. E. C. (1988). Categorization, accentuation and social judgement. British Journal of Social Psychology, 27, 147-157.

Miller, N., \& Harrington, H. J. (1992). Social categorization and intergroup acceptance: Principles for the design and development of cooperative learning teams. In R. Hertz-Lazarowitz \& N. Miller, (Eds.), Interaction in cooperative groups: the theoretical anatomy of group learning (pp. 203227). Cambridge University Press; New York.

Mullen, B., Brown, R. J., \& Smith, C. (1992). Ingroup bias as a function of salience, relevance and status: an integration. European Journal of Social Psychology, 22 103-122. 
Mummendey, A. \& Wenzel, M. (1999). Social discrimination and tolerance in intergroup relations: Reactions to intergroup difference. Personality and Social Psychology Review, 3, 158-174.

Oakes, P. J., \& Turner, J. C. (1990). Is limited information processing capacity the cause of social stereotyping? In W. Stroebe \& M. Hewstone (Eds.), European Review of Social Psychology (Vol. 1, pp. 111-135). Chichester: Wiley.

Rabbie, J. M., \& Horowitz, M. (1969). Arousal of ingroup-outgroup bias by chance win or loss. Journal of Personality E Social Psychology, 13, 269-277.

Roccas, S. \& Brewer, M. B. (2002). Social identity complexity. Personality and Social Psychology Review, 6, 88-106.

Sherman, J. W., Macrae, C. N., \& Bodenhausen, G. V. (2000). Attention and stereotyping: Cognitive constraints on the construction of meaningful social impressions. European Review of Social Psychology (vol. 11, pp. 145-175). Chichester: John Wiley \& Sons Ltd.

Stangor, C., \& Macmillian, D. (1992). Memory for expectancy-congruent and expectancyincongruent information: A review of the social and social developmental literatures. Psychological Bulletin, 111, 42-61.

Tajfel, H. (1969). Cognitive aspects of prejudice. Journal of Social Issues, 25, 79-97.

Tajfel, H. (1982). Social psychology of intergroup relations. Annual Review of Psychology, 33, 1-39.

Tajfel, H., Flament, C., Billig, M., \& Bundy, R. F. (1971). Social categorization and intergroup behaviour. European Journal of Social Psychology, 1, 149-178.

Tajfel, H., \& Turner, J. C. (1979). An integrative theory of intergroup conflict. In W. G. Austin \& S. Worchel (Eds.), The Social Psychology of Intergroup Relations (pp. 33-47). California: Brooks/Cole. 
Tajfel, H., \& Wilkes, A. (1963). Classification and quantitative judgement. British Journal of Social Psychology, 54, 101-114.

Turner, J. C. (1981). The experimental social psychology of intergroup behaviour. In J. C. Turner \& H. Giles (Eds.). Intergroup Behaviour (pp. 66-101). Oxford: Basil Blackwell.

Turner, J. C., Hogg, M. A., Oakes, P. J., Reicher, S. D., \& Wetherell, M. S. (1987). Rediscovering the Social Group: A Self-categorization Theory. Oxford: Blackwell.

Urada, D. I., \& Miller, N. (2000). The impact of positive mood and category importance on crossed categorization effects. Journal of Personality and Social Psychology, 78, 417-433.

Urban, L. M., \& Miller, N. (1998). A theoretical analysis of crossed categorization effects: A meta-analysis. Journal of Personality and Social Psychology, 74, 894-908.

van Knippenberg, A. V., \& Dijksterhuis, A. (2000). Social categorization and Stereotyping: a functional perspective. European Review of Social Psychology (vol. 11, pp. 105-144). Chichester: John Wiley \& Sons Ltd.

Vanbeselaere, N. (1987). The effect of dichotomous and crossed categorizations on intergroup discrimination. European Journal of Social Psychology, 17, 143-456.

Vanbeselaere, N. (1996). The impact of differentially valued and overlapping categorizations upon the differentiation between positively, negatively and neutrally evaluated social groups. European Journal of Social Psychology, 26, 75-96.

Waldzus, S. Mummendey, A. Wenzel, M. \& Weber, U. (2003). Towards tolerance: Representations of superordinate categories and perceived ingroup prototypicality. Journal of Experimental Social Psychology, 39, 31-47. 
Multiple categorization 28

Wenzel, M. (2001). A social categorization approach to distributive justice: Social identity as the link between relevance of inputs and need for justice. British Journal of Social Psychology, 40, 315335.

Wenzel, M., Mummendey, A., Weber, U., \& Waldzus, S. (2003). The ingroup as pars pro toto: projection from the ingroup onto the inclusive category as a precursor to social discrimination. Personality and Social Psychology Bulletin, 29, 461-473.

Wilder, D. A. (1986). Social Categorization: Implications for creation and reduction of intergroup bias. In L. Berkowitz (Ed.), Advances in Experimental Social Psychology, (Vol. 19 pp.293$355)$. 


\section{Endnotes}

${ }^{1}$ The dependent measures and models used were extensively pre-tested. The two models presented were of a boat and a crown. These were originally made in a pre-testing session with a group of students. Participants were informed that for the purposes of the pre-test the models would be referred to as 'model 1' and 'model 2'. Participants were required to rate model 1 and model 2 in terms of originality, creativity and artistic merit. For the boat; originality $t(13)=.069, p=0.95$, creativity $t(13)=-.623, p=.544$, and artistic merit $t(13)=.203, p=.842$. For the crown; originality $t(13)=.648, p=.528$, creativity $t(13)=1.27, p=.226$ and artistic merit $t(13)=1.72, p=$ .110. Which model was presented first as 'model 1' was counterbalanced across participants. The order of presentation of the models in the pre-test had no effect on participants' ratings of originality, creativity or artistic merit for either model. We combined the three scales into one overall measure for each model (boat Cronbach's $\alpha=.705$; crown Cronbach's $\alpha=.655$ ). When no reference was made to ingroup or outgroup affiliation of the person who made the model, both models were perceived to be equally positive, $t(14)=-1.20, p=.251$. We thus used these models and the three evaluative items in the subsequent experiment.

${ }^{2}$ One way t-tests were also computed against the scale midpoint of $\mathrm{O}$ (which would indicate no bias). There was no evidence of bias in the control condition, $t(19)=-.933, p=.363$, but there was significant ingroup favoritism in the multiple alternatives condition, $t(24)=-2.19, p=.038$.

${ }^{3}$ We decided to use only the most task-relevant item from the pilot evaluative measure here to provide the simplest test of our hypotheses. An additional pre-test was carried out to check that this 'creativity' item could indeed be considered a measure of positive evaluation. Fifteen participants were simply asked to rate the concept of creativity for valence on a scale anchored with negative at - 
5 , with neutral at 0 and with positive at +5 . Creativity was significantly perceived to be positive compared to the neutral midpoint: $t(14)=8.12, p<.001,(M=3.53)$.

${ }^{4}$ Although there appears to be outgroup favoritism in the multiple unrelated alternatives condition, this is evidently more attributable to the lowering of ingroup evaluations than to an increase in outgroup evaluations.

${ }^{5}$ The analysis was also computed just on the creativity item and revealed exactly the same pattern, $F$ $(1,52)=2.91, p=.063$ 
Table 1.

Evaluations as a function of categorization (Experiment 1).

\section{Task}

Control Multiple unrelated alternatives

Ingroup

7.27

Outgroup

5.60

Intergroup Bias

Note: Higher numbers indicate more favourable evaluations for ingroup and outgroup evaluations, but for intergroup bias higher numbers indicate more ingroup favoring bias. Standard deviations are shown in parentheses. 
Table 2.

Evaluations as a function of categorization (Experiment 2).

\begin{tabular}{|c|c|c|c|}
\hline & \multicolumn{3}{|c|}{ Task } \\
\hline & \multirow{3}{*}{ Control } & Multiple & \multirow{3}{*}{$\begin{array}{l}\text { Multiple } \\
\text { Related alternatives }\end{array}$} \\
\hline & & Unrelated & \\
\hline & & alternatives & \\
\hline \multirow[t]{2}{*}{ Ingroup } & 6.45 & 5.97 & 6.74 \\
\hline & (1.11) & $(1.73)$ & $(.904)$ \\
\hline \multirow[t]{2}{*}{ Outgroup } & 6.16 & 6.62 & 6.35 \\
\hline & (1.18) & (1.59) & $(1.36)$ \\
\hline \multirow[t]{2}{*}{ Intergroup Bias } & .249 & -.650 & .338 \\
\hline & $(1.26)$ & (1.38) & (1.18) \\
\hline
\end{tabular}

Note: Higher numbers indicate more favourable evaluations for ingroup and outgroup evaluations but for intergroup bias higher numbers indicate more ingroup favoring bias. Standard deviations are shown in parentheses. 